English Language and Linguistics, 24.4: 719-744. C Cambridge University Press 2019. This is an Open Access article, distributed under the terms of the Creative Commons Attribution licence (http://creativecommons.org/licenses/by/4.0/), which permits unrestricted re-use, distribution, and reproduction in any medium, provided the original work is properly cited.

\title{
'Fifty pounds will buy me a pair of horses for my carriage': the history of permissive subjects in English ${ }^{1}$
}

\author{
GEA DRESCHLER \\ Vrije Universiteit Amsterdam \\ (Received 12 June 2018; revised 24 May 2019)
}

\begin{abstract}
This article investigates the history of so-called permissive subjects in English, for example The tent sleeps four: inanimate, non-agentive subjects used with verbs that normally take animate, agentive subjects. Although permissive subjects are assumed in the literature to be innovations, there is little information available on their use and frequency. Using historical corpora, I provide an account of the history of permissive subjects with five verbs - see, buy, seat, sleep and sell. The results show that permissive subjects with see and buy are already found in the sixteenth century, while those with seat and sell occur from the nineteenth century onwards, and those with sleep first occur in the twentieth century. The five types also differ in other respects, with genre and functional motivations playing an important role. Crucially, there is an increase in the overall use of these permissive subjects, which follows the increase in subject-initial clauses and a more marked use of the presubject position as described by Los \& Dreschler (2012), supporting their proposal that several subject-creating strategies - passives, middles and permissive subjects - became more frequent in English due to changes in the pragmatic character of the clause-initial position, in turn caused by the loss of verb second.
\end{abstract}

Keywords: permissive subjects, semantic roles, history of English, verb second, unmarked theme

\section{Introduction}

There is a strong cross-linguistic tendency for grammatical subjects to express the semantic role of agent (e.g. Givón 1984; Comrie 1989). However, Present-day English (PDE) allows a wider range of semantic roles to function as the subject, including instruments, as in The hammer broke the window (Givón 1984; Levin 1993; Saeed 2016). In addition, as described by Rohdenburg (1974), Hawkins (1986) and Levin (1993), there is another puzzling set of subjects, illustrated in (1)-(2).

\footnotetext{
${ }^{1}$ I would like to thank the audiences at ICEHL19, SHES2017 and various colleagues for discussions about the topic of this article; and in particular Bettelou Los and Laura Rupp for feedback on an earlier version of the text. I would also like to thank two anonymous reviewers and the editor, Laurel Brinton, for their detailed and extremely helpful comments and suggestions. The example sentence in the title is taken from CLMET, Charles and Charlotte by Samuel Jackson Pratt (1777).
} 
(1) As for the brand new, this year saw collections from big names such as Kazuo Ishiguro, Ha Jin, Chimamanda Ngozi Adichie, James Lasdun, and this parish's own AL Kennedy.

(2) Bindslev cottage sleeps four in two bedrooms and has fireplaces, rugs and cool hanging lights in its warm pine surrounds.

(www.theguardian.com, accessed 12 October 2017)

The subjects (in bold) in (1) and (2) do not constitute prototypical agentive subjects, but nevertheless they occur with verbs (underlined) that normally have animate agents: seeing and sleeping are actions performed by humans and animals, not by objects or concepts. These subjects have been discussed in different places in the literature: in contrastive studies of German and English (Rohdenburg 1974; Hawkins 1986), in overviews of argument structure (Levin 1993), in language acquisition studies (Callies 2006), in translation studies (Doms \& De Clerck 2015) and, finally, in the context of academic writing (Low 1999; Dorgeloh \& Wanner 2009). Despite this attention from a range of perspectives, there is no single definition and no definitive understanding of the subjects and verbs involved in this pattern.

Various authors have pointed out the usefulness of these so-called permissive subjects in PDE: they allow a non-agentive argument to occur as the subject, in theme position (cf. Halliday 1967), aligning the choice of a particular theme with principles of unmarked themes (Kirkwood 1978; Hawkins 1986). This property has been used to explain not only their occurrence in PDE, but also their introduction (Hawkins 1986). More recently, Los (2009), Los \& Dreschler (2012) and Dreschler (2015) have proposed that it is the changing pragmatic character of the theme position that is crucial: non-subjects have become increasingly marked in initial position, a development that started with the loss of verb second in the fifteenth century and continued in the following centuries. This loss meant that the language needed more strategies to place arguments in subject position, in turn leading to an increase in strategies for creating non-typical subjects: passives, middles and permissive subjects.

Rohdenburg (1974), Hawkins (1986) and Los \& Dreschler (2012) all describe permissive subjects as innovations, somewhere in the Early Modern period, but there are in fact few data on their frequency and use, either diachronically or synchronically. Crucially, what is missing is information about when these permissive subjects started to occur and when they became more frequent. This information is particularly important for the scenario presented by Los \& Dreschler (2012): in order for their scenario to work, permissive subjects would have to have been introduced following the changes in the use of the clause-initial position.

This article investigates permissive subjects with five verbs - see, buy, seat, sleep and sell - and aims to establish (i) the first occurrences of these subjects; (ii) their frequency in different periods; and (iii) the factors that characterise their use. Section 2 describes the status of permissive subjects in PDE, while section 3 reviews in more detail the proposals in the literature about their introduction. Section 4 explains the methodology and section 5 presents the results. Section 6 discusses the implications of the findings. 
2 Permissive subjects in Present-day English: definition and earlier research

In the simplest definition, permissive subjects are inanimate, non-agentive subjects that occur with verbs that normally take animate, agentive subjects; in other words, their core feature is that they do not express the semantic role of agent, the 'conscious initiator of an action' (Comrie 1989: 58). Here are some further examples from the literature.

(3) The latest edition of the book has added a chapter. (Hawkins 1986: 58)

(4) The book sold 10,000 copies. (Hawkins 1986: 59)

(5) That whole wheat flour bakes wonderful bread. (Levin 1993: 82)

(6) $\$ 5$ will buy (you) a ticket. (Levin 1993: 82)

The subjects in examples (3)-(6) are all inanimate and non-agentive: for example, a book, as in (4), cannot consciously sell something, and flour, as in (5), cannot bake something by itself. These examples illustrate not only the range of verbs that occur with these permissive subjects, but also the range of semantic roles for the subjects themselves: that whole wheat flour indicates the material used; the book and $\$ 5$ can be described as instruments; and the latest edition of the book could be seen as a location or space. Yet what makes these sentences stand out is not just that their subjects are non-agentive, but that they occur with verbs that would generally take a 'conscious initiator', where 'generally' means either the most frequent use of a verb or its original use historically.

Two studies in particular have attempted to provide an overview of the verbs and subjects involved in the permissive subjects pattern. Rohdenburg (1974) focuses on the types of verbs and describes at least twenty verb classes, such as 'predicates of winning, acquiring and losing' in (7), and 'capacity-designating predicates' in (8).

(7) This loses us the best centre forward.

(8) The ingredients bake 4 cakes.

(Rohdenburg 1974: 11-12)

Rohdenburg's work illustrates the wide range of verbs and subjects found in this pattern, yet his categorisation does not answer the question of what these verbs (or indeed, subjects) share. Levin (1993), on the other hand, focuses on the types of subjects, distinguishing between ten types. She treats these sentences like alternations such as active/passive: she proposes that there is a version with an agent subject and a prepositional phrase (PP), and a version in which this 'oblique' phrase becomes the subject and the original subject is deleted. Example (9) illustrates her 'Time Subject Alternation' and (10) her 'Location Subject Alternation'.

(9) (a) The world saw the beginning of a new era in 1492.

(b) 1492 saw the beginning of a new era.

(10) (a) We sleep five people in each room.

(b) Each room sleeps five people.

(Levin 1993: 79, 82) 
However, it is doubtful that the permissive subjects behave as systematically as this; for instance, (10a) is questionable in acceptability. ${ }^{2}$ In Levin's view, permissive subjects represent a syntactic operation, but it is unclear what that syntactic operation would constitute, as there is no obvious change in argument structure.

Permissive subjects share some properties with middles, as in (11), but are crucially different syntactically.

(11) 'Quality drama sells really well in English language markets but non-fiction sells across the board,' says Wood.

(www.theguardian.com, accessed 4 January 2019)

Like permissive subjects, middles are used with verbs that would normally take an agentive subject, but that in the middle take a non-agentive subject (Hundt 2007: 9); drama and non-fiction in (11) do not consciously sell something. Another shared property is that middles often have a generic reading, describing a property of the subject rather than relating a specific event (Keyser \& Roeper 1984: 384); permissive subjects with seat and sell have a similar interpretation. However, middles always carry with them a passive interpretation, involving an implied agent or external argument (Hundt 2007: 15-17; Levin 1993: 26). This is not a typical characteristic of permissive subjects: sentences such as This tent sleeps four or 1492 saw the beginning of a new era do not have such an implied agent. Another difference is that middles undergo a detransitivisation process: compared to the transitive version, middles lack one argument - crucially, the agent (Hundt 2007: 7). In contrast, clauses with permissive subjects are still transitive (Levin 1993: 79). Technically, then, there is no change in transitivity or in argument structure, but rather permissive subjects represent an unusual choice for the argument that functions as an agent.

There is also another set of verb alternations that permissive subjects seem to be related to, the causative/ergative alternation illustrated in (12a) and (12b), which goes back to Old English (OE; van Gelderen 2011: 116).

(12) (a) The little boy broke the window.

(b) The window broke.

(Levin 1993: 3)

The window in (12b) is inanimate but not permissive - it is not equivalent in semantic role to The little boy in (12a). As in middles, there is a change in argument structure and the verb is no longer transitive. Some of these verbs, however, also allow a permissive subject in PDE, as illustrated in (13).

2 The Corpus of Contemporary American English (COCA, Davies 2008) contains only one example of sleep in this use with an animate subject, while the Brigham Young University-British National Corpus (BYU-BNC, Davies 2004) contains none. 
(13) (a) David broke the window with a hammer.

(b) The hammer broke the window.

(Levin 1993: 80)

Here, the hammer seems to take the place of David in terms of its relation to the verb. Unlike in (12), there is no change in transitivity between (13a) and (13b), making this a crucially different alternation - and a more recent one. As Los (2018) points out, both middles and the causative/ergative alternation may have facilitated the development of permissive subjects because of their tolerance for inanimate, non-agentive subjects.

It is not only the verbs that are involved in other processes: the subjects are too. Some of the examples presented in the literature seem to represent cases of metonymy: ${ }^{3}$ using one expression to refer to an element connected to it, for instance 'The Times' for 'the reporter from the Times' (Lakoff \& Johnson 1980: 35). Consider examples (14) and (15).

(14) This hotel forbids dogs. (Hawkins 1986: 58)

(15) Ealing hospital treated seven victims of the blast. (Callies 2006: 127)

In (14), the sentence means that the management of the hotel (i.e. people) forbid the presence of dogs; similarly, in (15), the hospital is used to refer to the people working at the hospital, rather than the hospital itself being interpreted as an agent (cf. Lakoff \& Johnson 1980: 38). The real referents here, the management and staff, are typical animate subjects, which means that examples such as these, where it is possible to determine human beings as the intended referents, will be excluded from the current study.

In other examples, the subjects can be seen as personifications:

(16) A computer crash has delayed all international flights in Japan. (Callies 2006: 124)

(17) Next month sees Garbage and Lenny Kravitz in town. (Callies 2006: 120)

(18) This paper argues that [...] epistemological guidelines can be established. (Dorgeloh \& Wanner 2009: 527)

In these examples, the events are given some properties of animate referents, making it appear as if they can 'initiate' or cause something to happen (cf. Lakoff \& Johnson 1980: 33). In contrast to the metonymical examples in (14) and (15), the subject does not act as a referring expression for an animate entity, but the inanimate subject is given some agentive properties. ${ }^{4}$ It is unclear to what extent permissive subjects are distinct from personifications, and in the present article, personifications will be included. Nevertheless, there seems to be a difference between personification for stylistic reasons and common patterns such as (17), which may no longer be recognised as personifications.

An interesting property of permissive subjects is that some types seem tied to specific genres. Examples with seats number or sleeps number are typical for advertising

3 Callies (2006: 113) claims that permissive subjects are not examples of metonymy or metaphor, but bases this conclusion on the properties of typical animate subjects, which permissive subjects are not.

4 This paper argues could also been analysed as a case of metonymy, where This paper stands for the author of the paper, but I will follow Low (1999) in analysing it as a personification. 
language, allowing a concise formulation without unnecessary detail (a quick Google search for seats, for instance, mostly yields examples from websites renting out accommodation). Another set of examples is especially frequent in academic writing, where verbs such as discuss or investigate are used with subjects like paper or article (Low 1999). Dorgeloh \& Wanner (2009) explain the use of this so-called 'paper construction' in academic writing - which they find is first used in the twentieth century - by pointing out specific requirements of the genre, focusing on rhetorical functions such as allowing the author to leave him/herself unmentioned. A study by Seoane \& Hundt (2017) further illustrates that this choice is not just linguistic, but stylistic, with important differences between disciplines in the amount of so-called authorial involvement. Impersonalisation strategies can also be relevant for other permissive subjects; for example, 1492 saw... replaces In 1492 we/people saw.... It is clear that any investigation into permissive subjects needs to take genre into account.

In sum, although permissive subjects have received some attention in the literature, their properties are not yet well understood. Specifically, both the syntactic and semantic properties of these subjects are still open to debate, most likely because of the wide range of subjects and verbs used. While it is possible to find some subpatterns seats and sleeps both seem descriptions of capacity, comparable to the generic reading of middles; this paper discusses and 1492 saw are impersonalisation strategies - it is difficult to find an underlying pattern that connects all permissive subjects. ${ }^{5}$

\section{Permissive subjects as innovations}

Permissive subjects are generally assumed to be innovations, despite the lack of detailed studies on their history. Rohdenburg (1974) discusses only one example, with lose, as support for a statement about their introduction. Hawkins (1986), in turn, proposes that permissive subjects are the result of a process whereby the distinction between transitive and intransitive verbs became less clear, a process that he claims - referring to Lightfoot (1979) - started in the Middle English period; indeed, Visser (1963: §163) provides examples for middles from the fifteenth century onwards. Hawkins uses Kirkwood's (1978) explanation for the use of permissive subjects in PDE, which is based on the restrictions caused by the fixed word order, to account for their introduction: the loss of case distinctions led to a fixed order, which limited reordering options and paved the way for unusual subjects. However, without a further analysis of non-subjects in initial position, this account does not explain why PDE still allows certain, but not all, adverbials to occur before the subject.

A more recent account, described in Los (2009), Los \& Dreschler (2012) and Dreschler (2015), specifically addresses this aspect of the initial position in an investigation into the

\footnotetext{
5 An anonymous reviewer has pointed out the possibility of a Construction Grammar analysis. Such an analysis still faces the challenge of identifying the common properties of all permissive subjects, but it certainly seems a promising option, as it lends itself well to accounting for connections between the various (sub)types. I leave this matter for future research.
} 
consequences of the loss of verb second in English. This system - characteristic of West Germanic languages - stipulates that the finite verb always occurs in second position in the main clause. While OE had a version of this system, verb-second word orders started to become less common in the language during the fifteenth century and all but disappeared after that (see Fischer et al. 2000 for an overview). Los \& Dreschler (2012) propose that the verb-second system brings with it a specific use of the initial, presubject position in the clause, which they call local anchoring: providing an unmarked (i.e. pragmatically neutral) link to the immediately preceding discourse. An example is given in (19).

(19) Mid pam wunode an moeden morlice drohtnigende,

with that dwelt a virgin virtuously living

'With him dwelt a virgin, living virtuously,' (coaelive [Basil]:468.786; Dreschler 2015: 249)

The clause-initial PP Mid pam refers back to a priest mentioned in the preceding clause and thus constitutes an information-structurally unmarked discourse-link. When the verb-second system was lost, the pragmatics of the initial position changed: it more often indicated contrast or emphasis (for instance, Outside, it was raining implies a contrast with the situation inside; time and place adverbials inherently exclude other options). The result is the current situation in PDE, where the subject is the only unmarked theme (Halliday 1967). It is this limitation on the theme position that leads to a need for strategies that create subjects out of arguments that would normally not qualify for subject status: strategies like middles, permissive subjects and passives, including cross-linguistically rare types.

Permissive subjects are especially interesting in light of these changes in the use of the first position because - when contrasted with alternative formulations - they allow a sentence in which subject and theme are aligned. Halliday \& Matthiesen (2014) describe the unmarked nature of the subject in theme position as the 'typical pattern' (2014: 97), from which speakers only deviate when there is a clear motivation to create a marked structure, for example to indicate contrast or emphasis. Consider the following examples of a permissive subject and possible alternative formulations.

(20) The cottage sleeps five.

(21) In the cottage, five people can sleep.

(22) Five people can sleep in the cottage.

In (20), The cottage is the theme and the subject. The sentence tells us something about the cottage and the message is that it provides space for five people. In (21), the theme is a PP containing the cottage, meaning that the cottage is still the starting point for the message. However, the grammatical form is now marked, with a PP in theme position. If we consider the context of an advertisement, where examples with sleep often occur, there is no likely reason to choose a marked theme: there is no obvious reason to put emphasis on in the cottage, unless the advertisement also describes other types of accommodation. Example (22), finally, has a subject as the theme, but having Five people as the subject means that the sentence adds new information about those 
people, rather than about the cottage. In sum, permissive subjects are a useful option in the grammatical system of PDE for expressing a particular element as the subject and hence as an unmarked theme.

Seen in this light, permissive subjects constitute a response to the changes in the use of the clause-initial position in English. In order for such a scenario to work, it is crucial that the introduction and/or increase in use of permissive subjects indeed follows the changes in the pragmatic character of the initial position. Even though a chronological order of events does not prove a causal connection, it can be the first step in determining whether there is a solid basis for a causal connection. Yet it is exactly these data on the diachronic development of the permissive subjects that are not available. Dreschler (2015: 302) provides data on the frequency of subject-initial main clauses in English between 1500 and 1914 which can be used as the baseline against which to compare the development of the permissive subjects. In the first subperiod, 1500-69, just over 50 per cent of the clauses start with a subject. This percentage increases steadily throughout the following subperiods, until it reaches 72.6 per cent in the period 18401914. If permissive subjects are indeed a response to this preference for subject-initial clauses, we would expect them to become more frequent - in both type and token over the course of this same period.

\section{Corpora and method of selection}

The corpus study includes the following five types of subject-verb combinations.

(23) Period sees: The past decade saw more diversity in design than any previous recent decade, (COHA, 1973, Non-fiction)

(24) Money buys: Twenty cents buys you a crispy chicken wing for dipping into scalding crimson hot sauce... (COHA, 2007, Magazines)

(25) Object seats number: The city's handsome new stadium seats 51,000 for baseball, 57,000 for football. (COHA, 1965, Magazines)

(26) Object sleeps number: This bed can sleep two very full-size adults with ease, (COHA, 1993, Magazines)

(27) Book sells copies: Her $\mathbf{7 2 3}$ romance novels sold more than a billion copies. (COHA, 2000, Magazines)

This selection is based on the following considerations. These types are among the most common sentences listed in the literature as examples of permissive subjects and represent a range of different verbs and types of subjects. Dictionary entries for these five verbs explicitly mention their permissive subject use (e.g. the online Oxford Dictionaries and Merriam-Webster). Finally, they are both systematic, because of either the type of subject or type of object, and at the same allow for some lexical variation, which makes them suitable for a corpus study. 
Table 1. Overview of corpora used

\begin{tabular}{lcc}
\hline \hline Name of corpus and reference & Time period & No. of words \\
\hline $\begin{array}{l}\text { EEBO (BYU), Early English Books Online } \\
\quad \text { (Davies 2017) }\end{array}$ & $1470 \mathrm{~s}-1690 \mathrm{~s}$ & $\sim 755$ million \\
$\begin{array}{l}\text { CLMET3.1, The Corpus of Late Modern English Texts, } \\
\quad \text { version 3.1 (De Smet, Flach, Tyrkkö \& Diller 2015) }\end{array}$ & $1710-1920$ & $\sim 40$ million \\
$\begin{array}{l}\text { COHA, The Corpus of Historical American English } \\
\quad \text { (Davies 2010-) }\end{array}$ & $1810 \mathrm{~s}-2000 \mathrm{~s}$ & $\sim 400$ million \\
\hline \hline
\end{tabular}

Table 1 provides an overview of the corpora that were used for the present study. ${ }^{6}$ COHA and EEBO were searched using the BYU online interface; AntConc (Anthony 2018) was used to search CLMET (both the text files and files tagged for parts of speech). In addition, the Oxford English Dictionary (OED) was also used for reference.

Various strategies were combined to search the corpora. To search for Period sees and Money buys, specific nouns were combined with forms of the verbs see and buy, including infinitives, participles and combinations with modals. The selection of nouns was based on examples presented in the literature as well as explorations of collocations with see and buy in various periods of the corpora. For Period sees, singular and plural forms of the following nouns were selected: year, day, morning, evening, decade, century, as well as seasons and numbers for years. For Money buys, the queries included money, dollar, dime, coinage, coin, penny, shilling, silver, pound, nickel, jewel, cent, diamond. For queries in EEBO, spelling variants were included and to make the task manageable (for see, for example, 669 examples were excluded, and only 39 relevant hits selected), only the most frequent types from COHA were included (day, year, morning and evening for see and pound, money, gold for buy). The permissive subjects for seat, sleep and sell occur with a range of subjects that are difficult to specify lexically; however, the permissive subject use only occurs with a specific type of object: a number for seat and sleep, and a number followed by copies for sell. Therefore, to search for seat and sleep I combined all forms of the verb and stipulated that it should be followed by a cardinal number, using the POS-tag in COHA. To search for sell, I combined forms of the verb with copies, and up to seven random words between the verb and copies (to allow for sold four copies and sold more than a million copies). The results of the queries were all checked manually; many examples were excluded because the verb was not in fact combined with an inanimate subject (for example, we on this day saw) or the syntax was different (for instance, there were seated two men);

\footnotetext{
6 The Penn-Helsinki Parsed Corpus of Early Modern English (Kroch, Santorini \& Delfs 2004) and the PennHelsinki Parsed Corpus of Modern British English (Kroch, Santorini \& Diertani 2010) were initially also included but they did not contain any relevant examples, in all likelihood because they are too small for an infrequent phenomenon like permissive subjects.
} 
to illustrate, for COHA, between 20 per cent (Period sees) and 89 per cent (Object sleeps) of hits were excluded.

5 Results: the history of permissive subjects

This section presents the results per subject-verb combination, followed by a comparison of all five types with respect to frequencies and genre.

\subsection{Period sees}

See as a verb has been present in English since the OE period. The first meaning given in the $O E D$ is for a transitive use: 'To perceive ... with the eyes, or by the sense of which the eye is the specific organ' (OED see v., 1.a). This description inherently applies to humans and animals, but the same entry also includes uses of a figurative meaning, as in (28).

(28) 1869 The place only sees the sun for a few hours in winter. (H. F. Tozer Res. Highlands of Turkey)

This example already represents a permissive subject, with a location as subject instead of a time expression. More importantly, sense $10 \mathrm{f}$ gives the following use specifically for inanimate subjects: 'To be marked by (an event)'. Some, but not all, of the examples here are of the type Period sees, with an early example from the eighteenth century.

(29) 1739 Hail the Day that sees Him rise, Ravish'd from our wishful Eyes. (C. WeSLEY Hymns \& Sacred Poems)

(30) 1895 A bright cold morning saw us in the saddle at 6.15. (F. B. WORKMAN \& W. H. Workman Algerian Mem.)

The present corpus study resulted in a total of 715 examples: 39 examples in EEBO, 25 in CLMET, and 651 in COHA. The first five examples from EEBO are given in (31)-(35).

(31) 1604 that yeare which saw an Angell tell daniel of an Eternall kingdome (EEBO, Hugh Broughton, Advertisement of corruption)

(32) 1612 that my yeares neuer see change of such grace to me, (EEBO, Thomas Sorocold, Supplications of Saints)

(33) 1618 and bright arcturus fire, the rosie-fingerd morning sees arise; (EEBO, George Chapman, Georgicks of Hesiod)

(34) 1621 our potter, whose deuine command can dash vs earthen vessels in one whom th' morning sees so proudly go, (EEBO, Richard Brathwaite, Nature's Embassy)

(35) 1635 the prince riseth with the day, and the morning sees him begin his prayers after the turkish manner (EEBO, Edward Grimeston, History of the Imperial Estate)

These examples are all roughly a century earlier than the first example from the $O E D$ in (29). The first examples are followed relatively quickly by other examples, i.e. they are not isolated examples. The sentence structure of the texts in EEBO is not always straightforward and sometimes it is difficult to determine what the intended subject of 
Table 2. Frequency of Period sees in EEBO, CLMET and COHA per million words ${ }^{7}$

\begin{tabular}{lccccccccc}
\hline \hline Period/ & & $1470-$ & $1570-$ & $1640-$ & $1710-$ & $1780-$ & $1850-$ & $1920-$ & $1990-$ \\
Corpus & & 1569 & 1639 & 1709 & 79 & 1849 & 1919 & 89 & 2009 \\
\hline EEBO & $n$ & 0 & 7 & 32 & - & - & - & - & - \\
& pmw & 0.00 & 0.02 & 0.07 & - & - & - & - & - \\
\multirow{2}{*}{ CLMET } & $n$ & - & - & - & 0 & 7 & 18 & - & - \\
& pmw & - & - & - & 0.00 & 0.53 & 1.21 & - & - \\
COHA & $n$ & - & - & - & - & 36 & 212 & 290 & 113 \\
& pmw & - & - & - & - & 0.95 & 1.52 & 1.69 & 1.97 \\
\hline \hline
\end{tabular}

see is, for instance when there is a great distance between an animate subject and a verb with an ellipted subject. Many examples occur in poetry and fiction, where there might be a stylistic choice for personification of morning or day. However, there are enough clear examples to say that Period sees is used with the same sense as the PDE permissive subjects. Four of the examples in (31)-(35) are with a present tense, but this is not typical for later periods: 69 per cent (426/617) of the examples in COHA have a simple past tense.

Table 2 presents the frequency per million words of the Period sees examples in EEBO, CLMET and COHA. The subperiods for EEBO and COHA follow, as far as it was possible, the 69-year periods in CLMET. What becomes clear, first of all, is that this is not a very frequent type of expression, only reaching more than one occurrence per million words from the subperiod 1850-1919 onwards. There are examples in EEBO, but at a very low frequency. ${ }^{8}$ The first subperiod of CLMET does not contain any examples, but this is due to the smaller corpus size; we know from the EEBO data that the permissive subjects with see are already used. In CLMET and COHA, the numbers start higher than EEBO and continue to increase in subsequent periods.

The occurrences per million words do not reflect the number of times speakers choose to combine this verb with an inanimate subject. Table 3, therefore, gives the frequency of the permissive subjects against the total number of occurrences of see, sees, saw, seeing and seen in each subperiod (only verb forms were selected, using the parts of speech tags; in EEBO, spelling variants were included), given per 1,000 forms.

All corpora show an increase throughout the subperiods, but the numbers remain low: even in the last period, the permissive subject use does not reach 1 occurrence per 1,000

\footnotetext{
7 The word count given in the corpus documentation for CLMET is as follows: $12,182,064$ for $1710-79 ; 13,300,457$ for 1780-1849; and 14,858,239 for 1850-1919. The COHA documentation contains the number of words per decade. These numbers were combined to calculate the number of words per subperiod: $37,928,868$ for 1810 $49 ; 139,481,810$ for $1850-1919 ; 171,464,555$ for $1920-89 ; 57,356,791$ for $1990-2009$. The same was done for EEBO, resulting in $50,802,714$ for the subperiod $1470-1569 ; 298,100,311$ for $1570-1639$; and $456,978,091$ for 1640-1709. Note that EEBO only continues until 1700 and COHA starts at 1810 .

${ }^{8}$ EEBO contains reprints of the same works in different periods, which may affect the dates and frequencies.
} 
Table 3. Frequency of Period sees in EEBO, CLMET and COHA per 1,000 forms of $<$ see $>$

\begin{tabular}{lccccccccc}
\hline \hline Period/Corpus & & $1470-1569$ & $1570-1639$ & $1640-1709$ & $1710-79$ & $1780-1849$ & $1850-1919$ & $1920-89$ & $1990-2009$ \\
\hline EEBO & $n$ & 0 & 7 & 32 & - & - & - & - \\
& $<$ see $>$ & 68,555 & 390,809 & 665,534 & - & - & - & - & - \\
\multirow{2}{*}{ CLMET } & per 1,000 & 0.00 & 0.02 & 0.05 & - & - & - & - & - \\
& $n$ & - & - & - & 0 & 7 & 18 & - & - \\
& $<$ see $>$ & - & - & - & 18,690 & 25,153 & 31,180 & - & - \\
COHA & per 1,000 & - & - & - & 0.00 & 0.28 & 0.58 & - & - \\
& $n$ & - & - & - & - & 36 & 212 & 290 & 113 \\
& $<$ see $>$ & - & - & - & - & 68,579 & 300,822 & 342,844 & 116,130 \\
& per 1,000 & - & - & - & - & 0.52 & 0.70 & 0.85 & 0.97 \\
\hline \hline
\end{tabular}


forms of see. Overall, the permissive subjects do not represent a large category of uses for the verb see, which may not be surprising considering that see has many different meanings (16 main senses in the $O E D$ ).

A crucial aspect of the scenario presented by Los \& Dreschler (2012) is that the permissive subjects become more frequent because they are a way of placing an argument in theme position in an unmarked way in terms of information structure. Of course, this only applies to permissive subjects if the subject is indeed in theme position. In COHA, 57 examples in this database of Period sees (8.8 per cent), do not have the subject as the initial element in the clause; in counting these initial elements, subordinators and coordinators were not included as non-subjects, but all other words, phrases and adverbial subclauses were. In other words, the majority of these permissive subjects do indeed represent unmarked themes. The 57 non-subjects in initial position are all linking, circumstance and stance adverbials, which are all typical marked themes in PDE.

\subsection{Money buys}

Buy as a verb has been used since the OE period. The first meaning given in the $O E D$ is a transitive one, with a sense of human agency: 'To get possession of by giving an equivalent, usually in money; to obtain by paying a price; to purchase' (OED buy v., I.1.a). In addition, buy has a separate entry for use with inanimate subjects: 'Of things: To be an equivalent price for; to be the means of purchasing' (OED buy v., I.1.d.). The earliest example for this sense is given in (36).

(36) 1622 A London mingled colour cloth, would haue bought at Lisborne two chests of Sugar. (G. DE Malynes Consuetudo)

These examples are not exactly the same as the PDE Money buys examples - materials rather than the concept of money are said to buy something - but they do illustrate an early use of buy with inanimate subjects.

There are 138 examples in EEBO, 16 in CLMET, and 507 in COHA; 661 examples in total. Examples (37)-(41) give the first five examples from EEBO.

(37) 1568 if: 15: poundes doe buy me two clothes, how many clothes wil: 300 : poudes buye me of the same (EEBO, Humfrey Baker, Wellspring of sciences)

(38) 1571 iulianus hearinge at his banquet and feast, that moneye would bye the Empyre, (EEBO, Richard Rainolde, Chronicle of noble emperors)

(39) 1578 what hath bene so loued but money hath bought? (EEBO, Thomas Lupton, All for money)

(40) 1578 so they lose both their money, and that precious pearle which no money can buy agayne: (EEBO, Thomas White, Sermon at Pawles Crosse)

(41) 1583 it is great pytie that money should buy them out: (EEBO, Phillip Stubbes, Anatomy of abuses) 
Table 4. Frequency of Money buys in EEBO, CLMET and COHA per million words

\begin{tabular}{lccccccccc}
\hline \hline Period/ & & $1470-$ & $1570-$ & $1640-$ & $1710-$ & $1780-$ & $1850-$ & $1920-$ & $1990-$ \\
Corpus & & 1569 & 1639 & 1709 & 79 & 1849 & 1919 & 89 & 2009 \\
\hline EEBO & $n$ & 1 & 54 & 83 & - & - & - & - & - \\
& $\mathrm{pmw}$ & 0.01 & 0.18 & 0.18 & - & - & - & - & - \\
CLMET & $n$ & - & - & - & 2 & 7 & 7 & - & - \\
& $\mathrm{pmw}$ & - & - & - & 0.16 & 0.53 & 0.47 & - & - \\
COHA & $n$ & - & - & - & - & 25 & 145 & 237 & 100 \\
& $\mathrm{pmw}$ & - & - & - & - & 0.66 & 1.04 & 1.38 & 1.74 \\
\hline \hline
\end{tabular}

These early examples illustrate two factors that characterise the whole dataset. First, many examples have a modal auxiliary preceding the verb, as in (39), (40) and (41): 59.4 per cent of the examples in EEBO (82 of 138); 100 per cent of the examples in CLMET; 72 per cent of all examples (365/507) in COHA. It seems that the sentences describe a property or capacity of the subject, reminiscent of typical generic reading of middles. Second, many examples occur in relative clauses, as in (40): in EEBO, 25.4 per cent of the examples ( 35 of 138) occur in relative clauses ( 24 with a subject relative, 11 with an object relative). In COHA, 45.6 per cent (231 out of 507) of the examples are relative clauses with an object relative pronoun, roughly half with an ellipted relative pronoun. These examples seem to create a fixed expression: the best $X$ (that) money can buy. COHA also provides more information on the use of this type of permissive subject: money buys examples are particularly frequent in Fiction (274/507, 54 per cent) and Magazines (147/507, 29 per cent).

Table 4 presents the frequencies for the Money buys examples per million words in EEBO, CLMET and COHA. The table shows that the examples are found from the second half of the sixteenth century, and that there is an increase throughout all subperiods of the different corpora. In the period 1850-1919, this subject-verb combination first reaches a frequency of more than 1 per million words.

Table 5 shows the frequency of the Money buys-type against the total number of forms of buy, buys, bought and buying (only verb forms, including spelling variants) in EEBO, CLMET and COHA. The table repeats the increase in the first subperiods but at a quicker rate; in other words, although the subject-verb combination only slowly becomes more frequent overall, it more quickly becomes a more frequent use with the verb buy throughout these periods. The numbers for COHA are higher than those for CLMET in the two subperiods where they overlap, but both corpora show a decrease after 17801849.

In terms of the theme position, in 18 of the examples in $\operatorname{EEBO}$ ( 13 per cent), 2 examples in CLMET (12.5 per cent) and 32 examples in COHA (6.3 per cent), the subject is preceded by some other element, most of which are time, place or stance adverbials. An interesting example is the fronted object in (42). 
Table 5. Frequency of Money buys in EEBO, CLMET and COHA per 1,000 forms of $<$ buy $>$

\begin{tabular}{lccccccccc}
\hline \hline Period/Corpus & & $1470-1569$ & $1570-1639$ & $1640-1709$ & $1710-79$ & $1780-1849$ & $1850-1919$ & $1920-89$ & $1990-2009$ \\
\hline EEBO & $n$ & 1 & 54 & 83 & - & - & - & - \\
& $<$ buy $>$ & 4,121 & 19,816 & 28,645 & - & - & - & - \\
\multirow{2}{*}{ CLMET } & per 1,000 & 0.24 & 2.73 & 2.90 & - & - & - & - & - \\
& $n$ & - & - & - & 2 & 7 & 7 & - & - \\
& $<$ buy $>$ & - & - & - & 771 & 981 & 1,221 & - & - \\
COHA & per 1,000 & - & - & - & 2.59 & 7.14 & 5.73 & - & - \\
& $n$ & - & - & - & - & 25 & 145 & 237 & 100 \\
& $<$ buy & - & - & - & - & 2,449 & 17,759 & 38,799 & 15,818 \\
& per 1,000 & - & - & - & - & 10.21 & 8.16 & 6.11 & 6.32 \\
\hline \hline
\end{tabular}


(42) 1919 And all these things money can buy; but the thing that money can not buy is democracy. (COHA, Magazines)

Alignment of subject and theme would be possible here by making the sentence passive: All these things can be bought by money. However, the clause that follows clearly shows that a contrast is intended, which means there is a clear motivation to use a marked, i.e. non-subject, theme.

\subsection{Object seats number}

Compared to see and buy, seat is a relatively young verb in English, with the earliest examples in the $O E D$ dating from around 1600. The first meaning given in the $O E D$ is a transitive use: 'To place on a seat or seats; to cause to sit down' (OED seat, v., 1.a). Permissive subjects are not listed separately in the $O E D$, although two senses do mention inanimate subjects. Sense 1f includes the description 'Of a building, room, etc.: To afford sitting accommodation for.' The first example given here is from 1828-32, but it has an animate subject. The first example with an inanimate subject in the $O E D$ is from 1887.

(43) 1887 Each theatre should be registered and advertised as capable of seating $a$ specified number. (Pall Mall Gaz.)

The $O E D$ also gives a sense $8 \mathrm{a}$, which is described as 'furnish[ing] ... with seats' and includes the example given above. However, the other examples listed here are all passives and seem to involve unmentioned animate, rather than inanimate, subjects.

There are no examples of this type in EEBO and CLMET. In total, there are 230 examples in $\mathrm{COHA}$; the first five examples are shown in (44)-(48).

(44) $1852 \ldots$ an outlooking mass of granite spread itself smooth and wide enough to seat two or three people. (COHA, Fiction)

(45) 1854 The ride was delightful. Cars seating eight; clean, soft-cushioned, nice. (COHA, Non-fiction)

(46) 1854 We like the arrangement of the pews here, as in No. 2, but by our measurement they can be only four feet and a half long, each seating three persons ... (COHA, Magazines)

(47) 1856 The round table, just large enough to seat four comfortably, was elegantly spread with fine white damask, (COHA, Fiction)

(48) 1868 ... largest Catholic church in New' York, which will hold five thousand persons and seat four thousand, was filled to overflowing every morning of last November at five o'clock (COHA, Magazines)

All these examples are earlier than the example in the $O E D$ in (43). Interestingly, the first examples have a grammatical structure in which the combination of subject and verb is arguably less notable: (44) and (47) have a to-infinitive, (45) and (46) a present participle, and (48) is a relative clause with a conjoined structure of hold and seat. These could be a signs that the construction is not yet entirely acceptable for speakers 
Table 6. Frequency of Object seats number in COHA per million words

\begin{tabular}{lcccc}
\hline \hline Period & $1780-1849$ & $1850-1919$ & $1920-89$ & $1990-2009$ \\
\hline$n$ & 0 & 38 & 145 & 47 \\
pmw & 0.00 & 0.27 & 0.85 & 0.82 \\
\hline \hline
\end{tabular}

Table 7. Frequency of Object seats number in COHA per 1,000 forms of $<$ seat $>$

\begin{tabular}{lcccc}
\hline \hline Period & $1780-1849$ & $1850-1919$ & $1920-89$ & $1990-2009$ \\
\hline$n$ & 0 & 38 & 145 & 47 \\
$<$ seat $>$ & 2,646 & 8,142 & 7,357 & 1,336 \\
per 1,000 & 0.00 & 4.67 & 19.71 & 35.18 \\
\hline \hline
\end{tabular}

(see Warner 1982 and Dreschler 2015 on the introduction of the ECM passive and prepositional passive). This obscuring of the subject and verb combination is present in the whole dataset: there are 112 deleted subjects (of which 17 are coordinated), 21 infinitives, 80 present participles, and 57 relative clauses. Nevertheless, these first examples are from different genres in $\mathrm{COHA}$, and show a range of objects. As in the Money buys examples, many examples contain a modal preceding the verb (51 out of 230, 22.2 per cent), as in (48), indicating a capacity for seating a particular number rather than describing that the space is actually occupied; the infinitives also carry this meaning.

Table 6 presents the number of examples and occurrences per million words for each subperiod. The table shows that there is a considerable increase between the first and second subperiod in which this type is found, after which the number seems stable. Unlike Period sees and Money buys, this type never reaches one occurrence per million words.

Table 7 presents the frequency of these permissive subjects against the total occurrences of the verb seat (as before, all and only verb forms). The table shows that there is a considerable increase between each subperiod after the first occurrences, from roughly 4.5 per 1,000 forms to 19.5 and even more than 35 occurrences per 1,000 words in the last subperiod. In other words, this usage quickly becomes frequent for the verb seat.

Finally, in terms of theme position, of the examples that have a non-deleted subject, only three are not in initial position, but are preceded by adverbial subclauses.

\subsection{Object sleeps number}

Sleep as a verb has been in use since the OE period. The first meaning given in the $O E D$ is the general intransitive sense: 'To take repose by the natural suspension of consciousness' (OED sleep, v., I.1.a). The $O E D$ also gives several transitive uses of the verb, including one that lists permissive subjects, described as 'To provide with sleeping 
accommodation' (II.12). The first quotation given in the $O E D$ for this particular sense is from 1848, but interestingly, that example, given in (49), has a human subject. ${ }^{9}$

(49) 1848 She could eat fifty people in her house, but could not sleep half the number. (J. R. BARTLett Dict. Americanisms)

The first example with a non-human subject is from roughly forty years later:

(50) 1919 A sleeping-car sleeps thirty passengers. (H. L. MenCKEN Amer. Lang.)

Interestingly, both examples are taken from sources describing American usage, rather than primary sources, suggesting that these sentences may not be in general use at this point.

EEBO and CLMET do not contain any examples of this type. COHA contains 41 examples; the first five examples are given in (51)-(55).

(51) 1934 Most cars will seat or sleep 28 persons. (COHA, Magazines)

(52) 1936 Able to seat 40 passengers or sleep 20, [the new plane] will have a top speed of 230 m.p.h., (COHA, Magazines)

(53) 1944 ... a pink, gaudy, tricked-up house which boasted a Ming bed that slept seven, (COHA, Magazines)

(54) 1950 It [a land plane] should have eight gas turbine engines, a 5,000-mile range, should cruise at 350 miles per hour, sleep 72 passengers. (COHA, Magazines)

(55) 1951 [The modern mobile home] can sleep four in reasonable comfort and two in luxury. (COHA, Magazines)

Clearly, this type of permissive subject shows up quite late, well into the twentieth century. The first two examples are coordinated constructions with seat, which possibly influences the use of sleep in this configuration. The first examples occur relatively soon after one another, but all come from the same genre, Popular magazines (and indeed, overall 29 of the 41 examples, 70.7 per cent, are from this genre). As with the seat examples, there are several examples where the exact combination of subject and verb is obscured: there are 12 ellipted subjects (of which 5 coordinated) and 12 relative clauses. Only 14 examples of the 40 have the surface order of subject and finite verb. As before, this may be an indication of an as yet rather marginal construction. Finally, several examples ( 9 examples, 22.5 per cent) contain a modal verb, as is common with some other permissive subjects; yet even without a modal, the sentence describes a capacity, reminiscent of the generic reading of middles: example (53) is a statement that the bed has capacity for seven people, not that seven people actually sleep in it.

9 An anonymous reviewer points out that this example raises an interesting question about other verbs, such as eat, that possibly allowed permissive subjects in the past which have not been 'successful'. Another explanation is that one permissive subject triggers the use of another in this specific example, something that can also be seen in the following example with sleep and live from COHA: 'my bedroom [...] was completely taken up by a built-in bunk-bed complex; it slept four but, I realized, lived only one comfortably' (Fiction, 1999). 
Table 8. Frequency of Object sleeps number in COHA per million words

\begin{tabular}{lcccc}
\hline \hline Period & $1780-1849$ & $1850-1919$ & $1920-89$ & $1990-2009$ \\
\hline$n$ & 0 & 0 & 15 & 26 \\
pmw & 0.00 & 0.00 & 0.09 & 0.45 \\
\hline \hline
\end{tabular}

Table 9. Frequency of Object sleeps number in COHA per 1,000 forms of $<$ sleep $>$

\begin{tabular}{lcccc}
\hline \hline Period & $1780-1849$ & $1850-1919$ & $1920-89$ & $1990-2009$ \\
\hline$n$ & 0 & 0 & 15 & 26 \\
$<$ sleep $>$ & 3,611 & 12,800 & 16,033 & 6,578 \\
per 1,000 & 0.00 & 0.00 & 0.94 & 3.95 \\
\hline \hline
\end{tabular}

Table 8 presents the number of examples and the frequency of this type in COHA per million words. The table shows that there is a considerable increase between the two periods in which this type of permissive subject is found, but it is not possible to tell whether this is a genuine increase that will continue in further periods.

Table 9 shows the frequency of permissive subjects of this type against the total number of occurrences of sleep, sleeps, sleeping and slept (only verb forms) per period. The permissive subjects account for only a small number of occurrences of the verb sleep; nevertheless, the increase that we saw in Table 8 is repeated: from 0.94 per 1,000 forms in 1920-89 to 3.95 in 1990-2009.

In terms of theme position, there is only one example in which the subject is not the clause-initial element. It is preceded by the PP In other words, a linking adverbial that does not contain an argument that could function as the subject of the clause.

\subsection{Book sells copies}

Sell as a verb has been present since the OE period, although its main meaning has changed. The current main use is described as follows: 'To give up or hand over (something) to another person for money (or something that is reckoned as money) ...' (OED sell v., 3.a.). The $O E D$ also lists the use of sell as a middle, but more importantly, the 'Draft additions 1993' give the following meaning: 'Of a publication or recording: to attain sales of (a specified number of copies)', with the following two sentences as earliest examples.

(56) 1860 The Cornhill Magazine..having sold nearly a hundred thousand copies. (THACKeray Roundabout Papers)

(57) 1938 His novels sold fifteen thousand copies in their first year. (E. WAUGH Scoop) 
Table 10. Frequency of Book sells copies in COHA per million words

\begin{tabular}{lcccc}
\hline \hline Period & $1780-1849$ & $1850-1919$ & $1920-89$ & $1990-2009$ \\
\hline$n$ & 0 & 21 & 273 & 165 \\
pmw & 0.00 & 0.15 & 1.59 & 2.88 \\
\hline \hline
\end{tabular}

There are no examples in EEBO and CLMET, and 459 examples in total in COHA. The first five examples are shown in (58)-(62).

(58) 1867 The book sold to the extent of two millions of copies, ... (COHA, Magazines)

(59) 1867 A meritorious work of general interest, i. e. a book not addressed to any class, sect, or profession, that costs fifteen dollars, is considered successful in the United States if it sells three thousand copies. (COHA, Magazines)

(60) 1869 The little map was a marvellous hit. It sold to the extent of forty thousand copies before the public mind was turned to other scenes. (COHA, Magazines)

(61) 1872 The book ought to have sold 50,000 copies and made me a fortune, (COHA, Fiction)

(62) 1874 Occasional issues of the Spectator seem to have sold as many as fourteen thousand copies; (COHA, Magazines)

Like the Object seats and Object sleeps types, then, this is quite a recent addition to the range of permissive subjects. There are 95 examples where the permissive subject is a relative pronoun (20.7 per cent); another 48 examples (10.5 per cent) have a deleted subject, mostly because of coordination. As before, these may be signs that the combination is not yet fully accepted. Most remarkably, however, this type of permissive subject seems to be limited mostly to just one genre: 75.4 per cent of the examples occur in Magazines (346 of 459).

Table 10 presents the frequency of the examples per subperiod against the total number of words. The table shows that this type of permissive subject increases considerably in frequency from its first occurrence onwards (from 0.15 to 1.59), and it continues to increase in the following periods, reaching the highest frequency in the last subperiod of all five types included in this study. A possible explanation is that the specific type of text where these examples occur is overrepresented in COHA.

Table 11 presents the frequencies against the number of occurrences of sell, sells, selling and sold (verbs only). The table shows that Book sells copies comes to constitute a frequent pattern for this verb quite quickly, from just roughly 1 per 1,000 forms to 13.5 in the last subperiod.

As for the theme position, there are 75 examples (16.3 per cent) where the subject does not occur in sentence or clause-initial position (as before, discounting conjunctions and complementisers) but is preceded by an adverb, PP, or subclause. The majority of these are time adverbials, linking and stance adverbials, which are typical marked themes for PDE. 
Table 11. Frequency of Book sells copies in COHA per 1,000 forms of $<$ sell $>$

\begin{tabular}{lcccc}
\hline \hline Period & $1780-1849$ & $1850-1919$ & $1920-89$ & $1990-2009$ \\
\hline$n$ & 0 & 21 & 273 & 165 \\
$<$ sell $>$ & 3,334 & 17,367 & 33,025 & 12,234 \\
per 1,000 & 0.00 & 1.21 & 8.27 & 13.49 \\
\hline \hline
\end{tabular}

\subsection{Comparison of the five types}

This section presents the results of a comparison between the five types of permissive subjects with respect to overall frequencies and genre.

\subsubsection{Frequencies}

Figure 1 presents the frequencies of all types in different corpora, based on the frequencies per million words (the numbers are as in tables 2, 4, 6, 8 and 10). Because the data are from different corpora, there are no continuous lines throughout all periods.

Figure 1 illustrates the difference between the time of introduction for the various types of permissive subjects. Until around 1700, the only two types of permissive subjects that occur are Period sees and Money buys and they are used very infrequently (but see footnote 6 on the frequencies in EEBO). These two types become more frequent from the subperiod 1780-1849 onwards. This is also the period when Object seats first occurs, but it is still quite infrequently used. It is only in the twentieth century that this type becomes more frequent and the final two types - Object sleeps and Book sellsare introduced, both showing in increase, Book sells most dramatically. With the

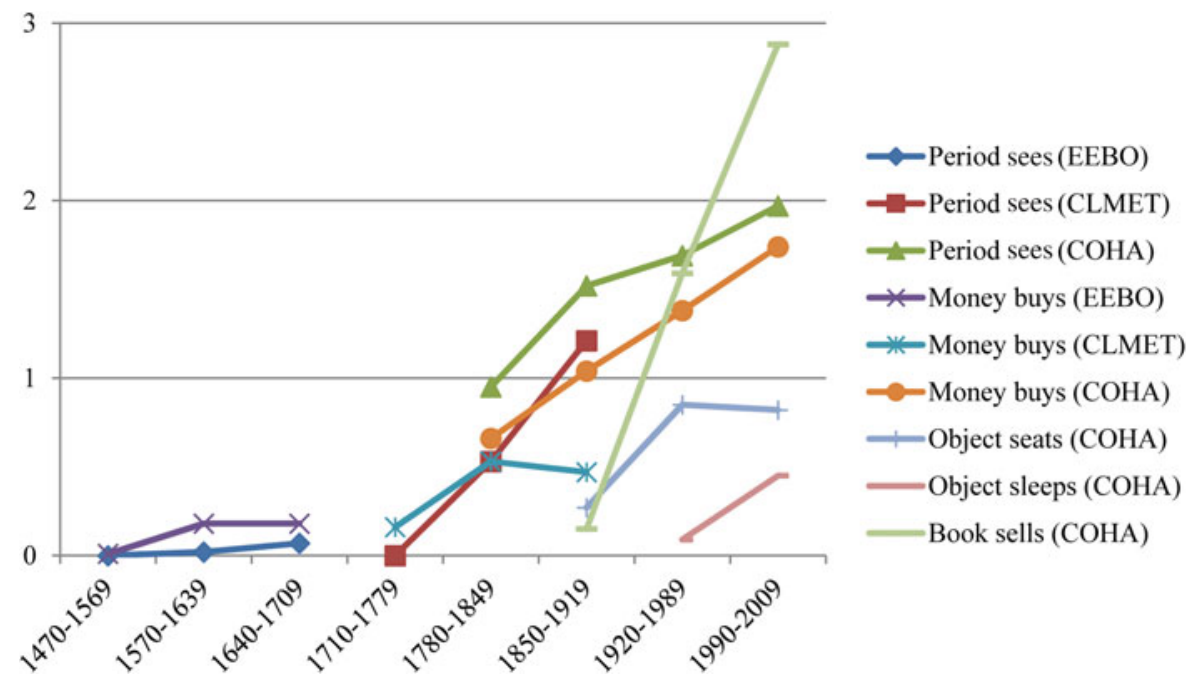

Figure 1. Frequency of permissive subjects per type and corpus per million words 
exception of Object sleeps, all types show an increase throughout the subperiods in $\mathrm{COHA}$, although at varying rates. Despite the somewhat scattered nature of these observations, these data do suggest there is an increase in both types and tokens for the permissive subjects from roughly 1800 onwards.

\subsubsection{A note on genre}

We have already seen that there may be specific motivations for using a particular type of permissive subject in a certain genre, for instance impersonalisation in academic writing, or conciseness in advertisements. The data from COHA can provide an insight into the influence of genre on the five types of permissive subjects because they allow a comparison of all five types across genre. Table 12 and figure 2 present the distribution of each type of permissive subject across the four genres in COHA: Non-fiction, News, Popular magazines and Fiction.

These data provide evidence for the observation that certain types of permissive subjects are especially common in certain types of texts. For three of the types of permissive subjects, Popular magazines has by far the largest percentage: Object seats (50.4 per cent), Object sleeps (70.7 per cent) and most extremely, Book sells copies

Table 12. Distribution of permissive subjects across genres in $\mathrm{COHA}$

\begin{tabular}{lccccc}
\hline \hline Genre & Period sees & Money buys & Object seats & Object sleeps & Book sells \\
\hline Non-fiction & $30.8 \%(190)$ & $9.3 \%(47)$ & $13.0 \%(30)$ & $0.0 \%(0)$ & $4.8 \%(21)$ \\
News & $12.3 \%(76)$ & $7.7 \%(39)$ & $19.6 \%(45)$ & $4.9 \%(2)$ & $14.8 \%(65)$ \\
Magazines & $37.3 \%(230)$ & $29.0 \%(147)$ & $50.4 \%(116)$ & $70.7 \%(29)$ & $79.0 \%(346)$ \\
Fiction & $25.1 \%(155)$ & $54.0 \%(274)$ & $17.0 \%(39)$ & $24.4 \%(10)$ & $6.2 \%(27)$ \\
Total & $100.0 \%(651)$ & $100.0 \%(507)$ & $100.0 \%(230)$ & $100.0 \%(41)$ & $100.0 \%(459)$ \\
\hline \hline
\end{tabular}

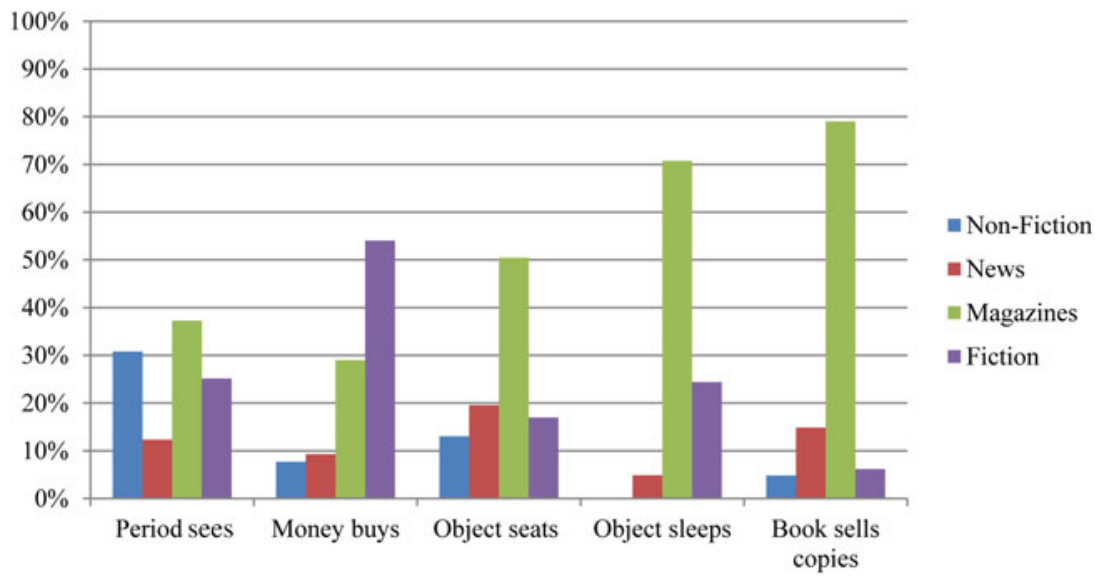

Figure 2. Distribution of permissive subjects across genres in COHA 
(79.0 per cent). Overall, Non-fiction and News do not seem to favour permissive subjects: they show the lowest percentages overall, ranging from 0 to 14.8 per cent, with two exceptions: 30.8 per cent of the Period sees examples occur in Non-fiction, while 19.6 per cent of the Object seats examples occur in News. Fiction shows more mixed results: Book sells copies hardly ever occurs (6.2 per cent), but Period sees and Money buys are relatively frequent (25.1 and 54.0 per cent, respectively). It is clear that more details are needed to determine which factors are involved in the choice of a permissive subject within a specific genre, and a more accurate understanding of the types of texts, since the COHA genre divisions are rather broad. Nevertheless, this general exploration does underline the role that genre clearly plays in the use of permissive subjects and may explain some of the restrictions on their use and, alternatively, their success.

\section{Conclusion}

This article has investigated permissive subjects with five verbs in corpora from the sixteenth century up to the present day. It aimed to establish when these permissive subjects start to occur, at what frequency, and in which grammatical contexts. The timing of the introduction and a possible increase is especially relevant in the scenario presented by Los \& Dreschler (2012), who argue that these permissive subjects are a response to a process in English whereby the subject has become the only unmarked theme, a process which started with the loss of verb second in the fifteenth century.

The results of the corpus study show that while some permissive subjects already occur around 1600, as suggested in the literature (e.g. Rohdenburg 1974 and Hawkins 1986), other types are quite recent innovations. Period sees and Money buys are already found in EEBO and continue to be used throughout all periods, showing an increase in frequency in CLMET and COHA. In contrast, the first examples of Object seats and Book sells copies are found much later, in the second half of the nineteenth century, and examples of Object sleeps occur first in the early twentieth century. Despite this mixed picture, these results suggest an overall increase in permissive subjects - in type and token - from around 1800 onwards. Of course, research on other permissive subjects besides these five types is needed to confirm and complete this picture.

An important finding, however, is that the five types are not only introduced at different points in time, but also behave quite differently. Some types are limited in their syntactic productivity or are limited to specific contexts or genres. For a full understanding, then, more detailed investigations of individual verbs are needed. It is likely that the individual nature of each type will become even more salient when other factors are considered: we have seen that genre plays a role, but the functional and stylistic motivations are also important, with factors such as impersonalisation, economy, and avoidance of the passive all possibly contributing to the use of certain permissive subjects.

Despite their differences, what all these permissive subjects share is that they allow a non-agentive argument, generally with a semantic role associated with adjuncts, to occur as the subject; indeed, the majority of the permissive subjects occur in theme 
position. The early date of the first permissive subjects with buy and see means that it is unlikely that the changing pragmatics of the clause-initial position as described by Los \& Dreschler (2012) are a direct, or even indirect, cause for their introduction. However, the need for subject-creating strategies may have contributed to the acceptance of these permissive subjects, which would explain the increase in their use in later centuries. Together with the increase in use of middles and passives, this may have helped the spread of the permissive subjects to other verbs, in an interesting interplay between syntax, semantics and information structure. The changes in argument structure for each individual verb together lead to a more general change in the system of the language: from a position with a close association to the semantic role of agent, the subject has developed into a syntactic position with a much looser connection to specific semantic roles.

Author's address:

Department of Language, Literature \& Communication

Vrije Universiteit Amsterdam

De Boelelaan 1105

1081 HVAmsterdam

The Netherlands

g.a.dreschler@vu.nl

\section{References}

Anthony, Laurence. 2018. AntConc (version 3.5.7). www.laurenceanthony.net/software (accessed 5 January 2019).

Callies, Marcus. 2006. Why money can't buy you anything in German: A functional-typological approach to the mapping of semantic roles to syntactic functions in SLA. In Janusz Arabski (ed.), Crosslinguistic influences in the second language lexicon, 111-29. Clevedon: Multilingual Matters.

Comrie, Bernard. 1989. Language universals and linguistic typology: Syntax and morphology. Chicago: University of Chicago Press.

Davies, Mark. 2004-. BYU-BNC. (Based on the British National Corpus from Oxford University Press). www.english-corpora.org/bnc (accessed 12 October 2017).

Davies, Mark. 2008-. The Corpus of Contemporary American English: 560 million words, 1990-present. www.english-corpora.org/coca/ (accessed 12 October 2017).

Davies, Mark. 2010-. The Corpus of Historical American English: 400 million words, 1810-2009. www.english-corpora.org/coha (accessed 12 October 2017).

Davies, Mark. 2017. Early English Books Online. Part of the SAMUELS project. www.englishcorpora.org/eebo/ (accessed 5 January 2019).

De Smet, Hendrik, Susanne Flach, Jukka Tyrkkö \& Hans-Jürgen Diller. 2015. The Corpus of Late Modern English (CLMET), version 3.1: Improved tokenization and linguistic annotation. KU Leuven, FU Berlin, U Tampere, RU Bochum. perswww.kuleuven.be/ u0044428/clmet3_1. $\mathrm{htm} /$ (accessed 12 October 2017).

Doms, Steven \& Bernard De Clerck. 2015. Translating English non-human subjects in agentive contexts: A closer look at Dutch. Across Language and Cultures 16(2), 285-310. 
Dorgeloh, Heidrun \& Anja Wanner. 2009. Formulaic argumentation in scientific discourse. In Roberta Corrigan, Edith A. Moravcsik, Hamid Ouali \& Kathleen Wheatley (eds.), Formulaic language, vol. 2: Acquisition, loss, psychological reality, and functional explanations, 523-44. Amsterdam: John Benjamins.

Dreschler, Gea. 2015. Passives and the loss of verb second: A study of syntactic and informationstructural factors. PhD dissertation, Radboud University Nijmegen.

Fischer, Olga, Ans van Kemenade, Willem Koopman \& Wim van der Wurff. 2000. The syntax of Early English. Cambridge: Cambridge University Press.

Gelderen, Elly van. 2011. Valency changes in the history of English. Journal of Historical Linguistics 1(1), 106-43.

Givón, Talmy. 1984. Syntax: A functional-typological introduction, vol. 1. Amsterdam: John Benjamins.

Halliday, Michael A. K. 1967. Notes on transitivity and theme in English: Part 2. Journal of Linguistics 3(2), 199-244.

Halliday, Michael A. K. \& Christian M. I. M. Matthiesen. 2014. Halliday's Introduction to Functional Grammar, 4th edn. London: Routledge.

Hawkins, John A. 1986. A comparative typology of English and German. London: Croom Helm.

Hundt, Marianne. 2007. English mediopassive constructions: A cognitive, corpus-based study of their origin, spread and current status. Amsterdam: Rodopi.

Keyser, Jay \& Thomas Roeper. 1984. On the middle and ergative constructions in English. Linguistic Inquiry 15, 381-416.

Kirkwood, Henry W. 1978. Options and constraints in the surface ordering of noun phrases in English and German. Journal of Pragmatics 2, 225-45.

Kroch, Anthony, Beatrice Santorini \& Lauren Delfs. 2004. The Penn-Helsinki Parsed Corpus of Early Modern English. www.ling.upenn.edu/ppche/ppche-release-2016/PPCEME-RELEASE-3

Kroch, Anthony, Beatrice Santorini \& Ariel Diertani. 2010. Penn Parsed Corpus of Modern British English. www.ling.upenn.edu/hist-corpora/PPCMBE-RELEASE-1/index.html

Lakoff, George \& Mark Johnson. 1980. Metaphors we live by. Chicago: University of Chicago Press.

Levin, Beth. 1993. English verb classes and alternations: A preliminary investigation. Chicago: University of Chicago Press.

Lightfoot, David W. 1979. Principles of diachronic syntax. Cambridge: Cambridge University Press.

Los, Bettelou. 2009. The consequences of the loss of verb-second in English: Information structure and syntax in interaction. English Language and Linguistics 13(1), 97-125.

Los, Bettelou. 2018. 'Permissive' subjects and the decline of adverbial linking in the history of English. In Hubert Cuykens, Hendrik De Smet, Liesbet Heyvaert \& Charlotte Maekelberghe (eds.), Explorations in English historical syntax, 23-49. Amsterdam: John Benjamins.

Los, Bettelou \& Gea Dreschler. 2012. The loss of local anchoring: From adverbial local anchors to permissive subjects. In Terttu Nevalainen \& Elizabeth C. Traugott (eds.), The Oxford handbook of the history of English, 859-71. Oxford: Oxford University Press.

Low, Graham. 1999. 'This paper thinks ...': Investigating the acceptability of the metaphor AN ESSAY IS A PERSON. In Lynne Cameron \& Graham Low (eds.), Researching and applying metaphor, 221-48. Cambridge: Cambridge University Press.

Merriam-Webster Dictionary online. www.merriam-webster.com (accessed 12 October 2017).

Oxford Dictionaries online. https://en.oxforddictionaries.com (accessed 12 October 2017).

OED $=$ Oxford English Dictionary online. www.oed.com (accessed 12 October 2017).

Rohdenburg, Günter. 1974. Sekundäre Subjektivierungen im Englischen und Deutschen: Vergleichende Untersuchungen zur Verb-und Adjektivsyntax. Bielefeld: Cornelson-Velhagen \& Klasing. 
Saeed, John I. 2016. Semantics, 4th edn. Chichester: Wiley-Blackwell.

Seoane, Elena \& Marianne Hundt. 2017. Voice alternation and authorial presence: Variation across disciplinary areas in Academic English. Journal of English Linguistics 46(1), 3-22.

Visser, F. Th. 1963. An historical syntax of the English language, vol. 1: Syntactical units with one verb. Leiden: Brill.

Warner, Anthony. 1982. Complementation in Middle English and the methodology of historical syntax. London: Croom Helm. 